\title{
Decentralized Urban Farming Through Keyhole Garden: a Case Study with Circular Economy and Regenerative Perspective
}

\author{
S. Venkata Mohan ${ }^{1}$ (1) $\cdot$ Manupati Hemalatha $^{1} \cdot$ K. Amulya ${ }^{1} \cdot$ G. Velvizhi ${ }^{1} \cdot$ P. Chiranjeevi ${ }^{1} \cdot$ Omprakash Sarkar $^{1}$. \\ A. Naresh Kumar ${ }^{1}$ • K. Vamshi Krishna ${ }^{1}$ • J. Annie Modestra ${ }^{1}$. Shikha Dahiya ${ }^{1}$. Dileep Kumar Yeruva ${ }^{1}$. \\ Sai Kishore Butti ${ }^{1} \cdot$ J. Shanthi Sravan ${ }^{1} \cdot$ Sulogna Chatterjee $^{1} \cdot$ Rajesh Kona $^{1}$
}

Received: 22 July 2020 / Revised: 8 October 2020 / Accepted: 12 October 2020 / Published online: 9 November 2020

(C) Springer Nature Singapore Pte Ltd. 2020

\begin{abstract}
Over the past few decades, access to abundant and easily available fossil sources aided in remarkable advancements in technologies and rapid urbanization. The unparalleled growth in population and migration of rural residents to the urban areas have transformed cities to hotspots for major anthropogenic activities, seminal contact points between natural and socio-economic activities, and areas responsible for generation of more than $80 \%$ of gross domestic product (GDP). This has placed cities at a crossroad of facing environmental grand challenges posed by population expansion, climate change, and depleting resources. Ushered by these problems, cities are directing the course of waste utilization towards sustainable production and consumption strategies by adopting the principles of circular economy (CE). This organic waste generated in huge quantities can be considered as a valuable resource in the urban biocycles. The present article highlights the importance of looping back this biogenic organic waste (domestic) to a certain extent in a decentralized way. It offers an eco-centric view to adopt circular urban food practices by constructing and operating a keyhole garden (KHG) as a case study. This approach works in synergy with nature and adopts the principles of biomimicry and cradle to cradle, wherein waste is reintroduced into the system as input resources or is metamorphosed to valuable materials. It underlines the role of $\mathrm{CE}$ approaches to spark this transformation and strategically direct the flow of valuable domestic waste resources to close the urban nutrient loops in a decentralized and regenerative approach. While the solutions to close the loop and recycle wastes address the end of pipe problems, the community-based innovation strategies aim at building resilience, producing food more locally, limiting the use of fertilizers, conserving water, and also combating climate change.
\end{abstract}

Keywords Composting · Urban biocycles - Waste valorization · Closing loop · Resilience - Regenerative agriculture · Permaculture $\cdot$ Sustainability

\section{Introduction}

In the year 2007, the urban population for the very first time exceeded the rural population (World Bank 2018). This was majorly due to rapid industrialization which was propelled by exponential use of fossils in a linear industrial economic model $\mathrm{CHu}$ et al. 2016; Venkata Mohan et al. 2020). Unprecedented use of

S. Venkata Mohan

svmohan@iict.res.in; vmohan_s@yahoo.com

1 Bioengineering and Environmental Sciences Lab, Department of Energy and Environmental Engineering (DEEE), CSIR-Indian Institute of Chemical Technology (CSIR-IICT), Hyderabad 500007, India these fossils resulted in greenhouse gas (GHG) emissions undermining the quality of our climate. Aside from the fact that they are impacting the environment, these resources are nonrenewable and are depleting rapidly. Three by fourth of the global resource consumption occurs in urban agglomerates, while only $10 \%$ of these resources are converted into products. The remainder either ends up as waste along the supply chain or is dispersed into the environment prior to reaching the customers (Haas et al. 2015). Resources are exported from outside urban boundaries and then are utilized within the boundaries to sustain the activities. The waste that is generated after use is stocked/deposited within the urban areas. Eighty percent of the products end up as waste in the landfills or are incinerated within 6 months of use and only $10 \%$ are recycled into new products (Haas et al. 2015). The materials that enter into a city are both renewable and non-renewable in 
origin and are used within the urban ecosystem to drive its functions. These input materials eventually result in outputs which are again renewable or non-renewable in origin and are termed as biological and technical materials, respectively (Venkata Mohan et al. 2020). The technical materials are reused, recycled, remanufactured, or refurbished while the biological materials are generally landfilled. The management of these wastes incur economic burden apart from deteriorating the environment and planetary sinks as well as polluting soil, water, and air (EMF 2019).

The urban-bound biological materials are a trove of valuable nutrients and energy, which can be looped back to the biogeochemical cycles and have the ability to support and restore the Earth's natural capital, decouple economic growth from escalating resource use, and close the concentrated linear nutrient cycles (Venkata Mohan et al. 2016a, 2020). For achieving this, a circular economy (CE) approach needs to be employed which tackles the limitations of linearly designed systems (Braungart and Mc Donough 2009; Venkata Mohan et al. 2016a; EMF 2013). The CE approach can be applied to every sector in the economy, and the concepts of $\mathrm{CE}$ have been centric mainly in the manufacturing sector (Sanchez et al. 2020). Further developments are required to apply these principles in the food and agriculture sector. This is because agriculture is undoubtedly the most pioneering human endeavour, both because it is the primary source of our food and also plays a key role in improving the livelihood and economic status of the population. Ushered by the industrial revolution and advancements in technology, the global profile of agriculture changed dramatically. Agriculture sector on the whole now occupies half of the plant-habitable surface of the planet; uses $69 \%$ of extracted fresh water; and, together with the rest of the food system, is responsible for 25-30\% of GHG emissions (Gladek et al. 2017). These modern agriculture practices use a variety of chemical inputs such as fertilizers and pesticides, heavy machinery, monocultures of crops in huge acres of land, and intensification of the animal husbandry. The net result is the use of huge quantities of energy and chemicals, air and water pollution, creation of dead zones, reduction in soil fertility, increased GHG emissions, and biodiversity loss, etc. None of these issues stands alone, and they are intricately linked among each other. Furthermore, they are also linked to declining livelihoods, poor health, lack of education, gender inequality, communication, transport, waste generation, and infrastructure (Leakey 2020). Given this background, alternate production and consumption models which are foregrounded by the principles of $\mathrm{CE}$ are required in the agri-food systems to overcome these problems and reverse the trends. Considering the fact that $80 \%$ of total food is projected to be consumed in urban areas by 2050 , cities can be viewed as beneficial hotspots for tailoring efforts towards development of circular practices in the agri-food system.
Therefore, the present article sets out to specifically explore the current urban food systems and it highlights the role of $\mathrm{CE}$ approaches in strategically directing the flow of valuable biological resources to close the urban nutrient loops. It presents an eco-centric view to adopt circular food practices by utilizing the concept of a keyhole garden (KHG) as a case study. The construction and operation of a KHG and how it can be one of the ways to close the nutrient loops, recycle wastes, and foster decentralized community-based innovations are discussed. The solutions to close the loop and recycle wastes in the system itself address the end of pipe problems by building resilience, producing food more locally, limiting the use of fertilizers, conserving water, and combating climate change.

\section{Urban Food Systems}

An urban food system is a hybrid food system which comprises various ways of food provisioning, i.e. a combination of different ways to produce, procure, distribute, or sell food in the urban areas (Wiskerke 2015). This may range from leafy vegetables that are grown within the city to other food items like rice which are grown and transported from the surrounding hinterlands or other processed food that are produced thousands of kilometres away. Some cities are majorly dependent on the intra-urban, peri-urban, and nearby hinterlands, while some others although not entirely but majorly rely on processed food from other countries. The food system in urban areas is intricately linked to global food provisioning. This globalized food system has brought a lot of advantages to the urban areas such as constant and year-long availability of food at lower prices. However, this also brought along with it some costs, like scarcity and depletion of natural resources (energy, land, and water), climate change, the need to feed the increasing urban population, and impact on health due to changing diets. Apart from this, waste is highly pervasive and cuts across all domains of life including the food sector. Food waste constitutes a major proportion of the municipal solid waste (MSW). Of the food (plant-derived, dairy, meat, and oils), 30\% is never consumed (FAO 2013). Despite taking adequate measures to avoid the waste, some proportion still end up as unavoidable waste that requires effective management and valorization (Dahiya et al. 2018). Food waste in the urban areas is majorly landfilled and also incurs cost and energy during collection and transportation of wastes to landfill sites. The repercussions of waste are not just confined to the urban areas but are rippled across the connected rural systems, where the food is produced, affecting the phosphorus and nitrogen cycles (Gustavsson et al. 2011). Added to this, the current COVID-19 pandemic also highlighted the longstanding food problems such as fragile food distribution systems, plummeting food supply chains, losses to food 
business such as restaurants, and limited access to food. The complexity of issues surrounding the current urban food systems and the need to reduce dependency on the surrounding hinterlands call for development of regenerative agricultural practices as well as resilient food systems (EMF 2017; Venkata Mohan et al. 2016b, 2020; De Bon et al. 2010).

\section{Regenerative Urban Food System Through Circular Economy Approach}

Various approaches have been proposed and/or implemented to propel transition towards circular food practices in the urban spaces (EMF 2019). Producing food within urban areas has been recommended as a way to simultaneously tackle a breadth of environmental, social, and health issues. The primary quick fix is to redistribute the surplus edible food to the needy populations. This will not only help in overcoming the problems of food wastage but will also aid in diverting the flow of food to landfills. In addition, circular practices with emphasis on organic waste streams, including food waste and peri-urban agriculture to reconnect the places of production (rural areas/hinterlands) to places of consumption (cities) to encourage the concept of 'food communities', are rapidly emerging (Venkata Mohan et al. 2016b; Dahiya et al. 2020). Gaining an understanding on their existing peri-urban production will enable cities to demand food that is not only grown regeneratively but also produced locally (EMF 2019). In return, the nutrients can be given back to the peri-urban farms in the form of organic fertilizers obtained from urban food products and wastes (EMF 2019). Other strategies include fostering innovation and creativity by designing new food products (single cell protein, an alternative to dairy and meat products) and processes which enable the use of bio-based products to replace the fossil-based materials (Venkata Mohan et al. 2016a, 2020; Sarkar et al. 2019).

Another important way to trigger change towards a better food system in the urban areas is to grow food locally through regenerative practices, which aid in improving the overall quality of an ecosystem (EMF 2019). This overarching concept includes many regenerative practices such as use of organic fertilizers, crop rotation, mixed farming, agroecology, agroforestry, and permaculture. According to Holmgren (2011), permaculture can be defined as "the use of systems thinking and design principles that provide the organising framework for implementing the above vision". Permaculture facilitates a conscious design of landscapes, which mimic the patterns and relationships found in nature, while yielding an abundance of food, fibre, and energy for provision of local needs (Holmgren 2011). It advocates integration of land, resources, people, and the environment through mutually beneficial synergies. The idea is to imitate the closed loop and no waste natural systems relying on three ethical guidelines, which are care for earth, care for people, and fair share (Holmgren 2007; Rhodes 2012). The characteristics of a well functioning permaculture technique include a wide variety of species, spaces and zones, diverse and abundant yield of food, and other useful products (Peeters 2011). Making the system resilient to environmental perturbations such as drought and the ability to sustain with the locally available and renewable inputs also are embedded in this technique (Nicholls and Altieri 2012). The key ingredient in all these strategies is working in synergy with the natural resourses and adopting the principles of $\mathrm{CE}$, biomimicry, and cradle to cradle. The key tenet of these strategies is that any material which is considered waste should be reintroduced into the system as input resources or should be metamorphosed to valuable materials (Venkata Mohan et al. 2019; Katakojwala and Venkata Mohan 2020), thus designing out waste and regenerating the natural systems. In the food sector, the application of industrial/urban ecology concepts in a CE perspective aids in connecting unlinked systems and supports the concept of recycling flows in the food systems network (Strazza et al. 2015). Transforming our linear food practices to a circular model presents environmental, health, and economic benefits both across the food supply chain and the society (Venkata Mohan et al. 2020; Dahiya et al. 2018, 2020).

\section{Keyhole Gardens}

The KHG is a circular raised garden bordered with stones and is also closely associated with permaculture practices. The original permaculture vision by Bill Mollison (a renowned researcher who promoted the theory and practice of permaculture) of growing gardens of food and useful plants rather than ornamentals is still an important example of the application of this principle (Holmgren 2011). KHG is a self-regenerating garden with a keyhole-shaped serration on one side and an organic composting circular unit in the centre (Hemenway 2015). KHG was first made popular in Africa, where water scarcity and the availability of fertile land were issues because of the persistent hot and dry climate. Initially, it was developed in Lesotho, Southern Africa, by the consortium for Southern Africa Food Security Emergency (C-SAFE) (Billingsley et al. 2013; http://www.fao.org/fileadmin/user upload/nutrition/docs/policies_programmes/CAADP/ southern_africa/presentations/DAY2_Ps3_Lesotho.pdf) to foster food security, education, income generation, community development, and nutrition. It was specifically focused on uplifting households affected with HIV and AIDS, chronically ill patients, and aged population. The idea is to reduce physical effort in these patients as these gardens require less maintenance and, at the same time, provide nutritious food such as spinach, onions, carrots, rapeseed, and beetroot apart from the staple corn and potatoes. Today, 
KHGs are found in many places across Africa (including Ethiopia, Rwanda, Kenya, Sudan, and Nigeria) and Asia (Allen 2018). They are being built as mostly in-house kitchen and fruit gardens to provide self-sufficiency and also highvalue crops using succession planting (Arias et al. 2013; Allen 2018). The underlying principle in KHG is to use different components synergistically so that the outcome is greater than what can be achieved through a single element. It can be easily incorporated into urban areas in a decentralized way, where land availability and water scarcity are major issues. The organic waste produced at the household level can be used as self-made compost in these gardens, reinvigorating backyard or community gardening. This will also help in reducing the amount of waste that is being sent to landfills and avoid the costs associated with waste collection, transport, and treatment. This approach also helps in building local networks of food and increases self-sufficiency of the urban areas (Gren and Andersson 2018). The use of biological waste materials for closing the nutrient loops and building resilient urban spaces will eventually support 'regenerating natural systems'.

\section{Case Study}

\section{Design and Construction of KHG}

A KHG was constructed at CSIR-Indian Institute of Chemical Technology (CSIR-IICT) and discussed as a case study. BEES lab at the CSIR-IICT works on waste valorization for the generation of bio-based products in an integrated approach. As a part of the work, the idea was to develop, evaluate, and demonstrate the function of a KHG in utilizing the nutrients of food waste obtained from the Institute's canteen. The construction of KHG was initiated on 10th February, 2017 (Fig. 1). Laboratory backyard was selected for the construction and the KHG was designed with proportionate dimensions with an area of $7 \mathrm{~m}^{2}$ and a diameter of $3 \mathrm{~m}$ (Fig. 1; Table 1). The KHG was positioned in a way that it gets exposed to sunlight and rainfall without any obstruction. The design of a KHG includes a compost bin, a drainage layer, and moisture-retaining layers comprising of dry leaves, papers,

Table 1 Details of KHG

\begin{tabular}{ll}
\hline Diameter of the garden & $3 \mathrm{~m}$ \\
Area of the garden & $7 \mathrm{~m}^{2}$ \\
Diameter of the compost pit & $0.34 \mathrm{~m}$ \\
Area of the key hole & $0.4 \mathrm{~m}^{2}$ \\
Height of the KHG above & $0.63 \mathrm{~m}(0.3 \mathrm{~m}$ below ground level $)$ \\
ground level & $0.9 \mathrm{~m}(0.2 \mathrm{~m}$ above the top soil layer \\
Height of the composting bin & of KHG \\
Effective area for plantation & $6.2 \mathrm{~m}^{2}$ \\
\hline
\end{tabular}

green chippings, and red loam soil (https://blog.agrivi.com). It was constructed using recycled materials like cardboards, used papers, broken bricks, stones, dried leaves, grass, twigs, and garden soil.

Initially, the area selected was dug upto $0.9 \mathrm{~m}$ (0.2 $\mathrm{m}$ above the top soil layer of $\mathrm{KHG}$ ) to make a keyhole-shaped structure and was thoroughly bordered. The outer border of the garden was built with broken bricks by fixing with cement and cardboard (with a rise of about $1 \mathrm{~m}$ from ground level) for rigidity (Figs. 1 and 2). The brick and cardboard wall give the garden its form, besides retaining all its contents inside, and also helps in trapping the moisture within (https://www.bobvila.com/ articles/keyhole-gardening/). A circular central basket (compost bin; area: $0.4 \mathrm{~m}^{2}$; diameter: $0.34 \mathrm{~m}$ ) with lateral perforations is placed in the centre of the KHG at a slight elevation from the ground level (Fig. 3). It serves as the area for supplying nutrients (in the form of waste) and water, facilitates composting, and supports percolating water through all the layers of the garden. The bottom layer of the compost bin was filled with stones (40-60 mm) (Fig. 1), which acts as a base layer for slow percolation of nutrients from the compost to the area of the KHG. The bottom of the dug area surrounding the compost pit was layered with cardboard, which was then sequentially overlaid with dried leaves, twigs and dried grass, waste paper, and red loam soil. This sequence was repeated multiple times up to a height of $0.3 \mathrm{~m}$ and until a base for the pit was attained. On this base the soil bed was laid for plantation until the desired height $(0.63 \mathrm{~m}$ above ground level) was achieved. Cardboard and waste paper act as an excellent source of carbon and means to absorb moisture, whereas dried leaves, twigs, and brown waste act as nutrient sources. The layers of the bed have an outward gradient towards the boundary walls, which helps in directing the moisture content from the central compost bin into the bed (Allen 2018). The top surface soil was layered slightly below the outer walls to prevent soil run-off and retain moisture. After the construction was complete, the KHG was watered for 3 days (Fig. 2). On the third day, a layer of garden soil was again added to raise the bed uniformly sloping towards edges, followed by wetting the soil. After the construction of KHG, an effective plantation area of $6.2 \mathrm{~m}^{2}$ was available for the study.

\section{Operation}

The KHG was maintained by adding food, fruit or vegetable wastes received from the Institute's canteen and leftovers from the lunch box of students in the lab into the composting bin at regular time intervals as planned along with the addition of grey water or rain water. During the study period, initially, $1 \mathrm{~kg}$ of wet biodegradable solid waste (composite vegetable, fruit, and food waste) was fed to compost bin once in 2 days, and later, it was fed twice a week $(0.4 \pm 0.2 \mathrm{~kg}$ per feeding 


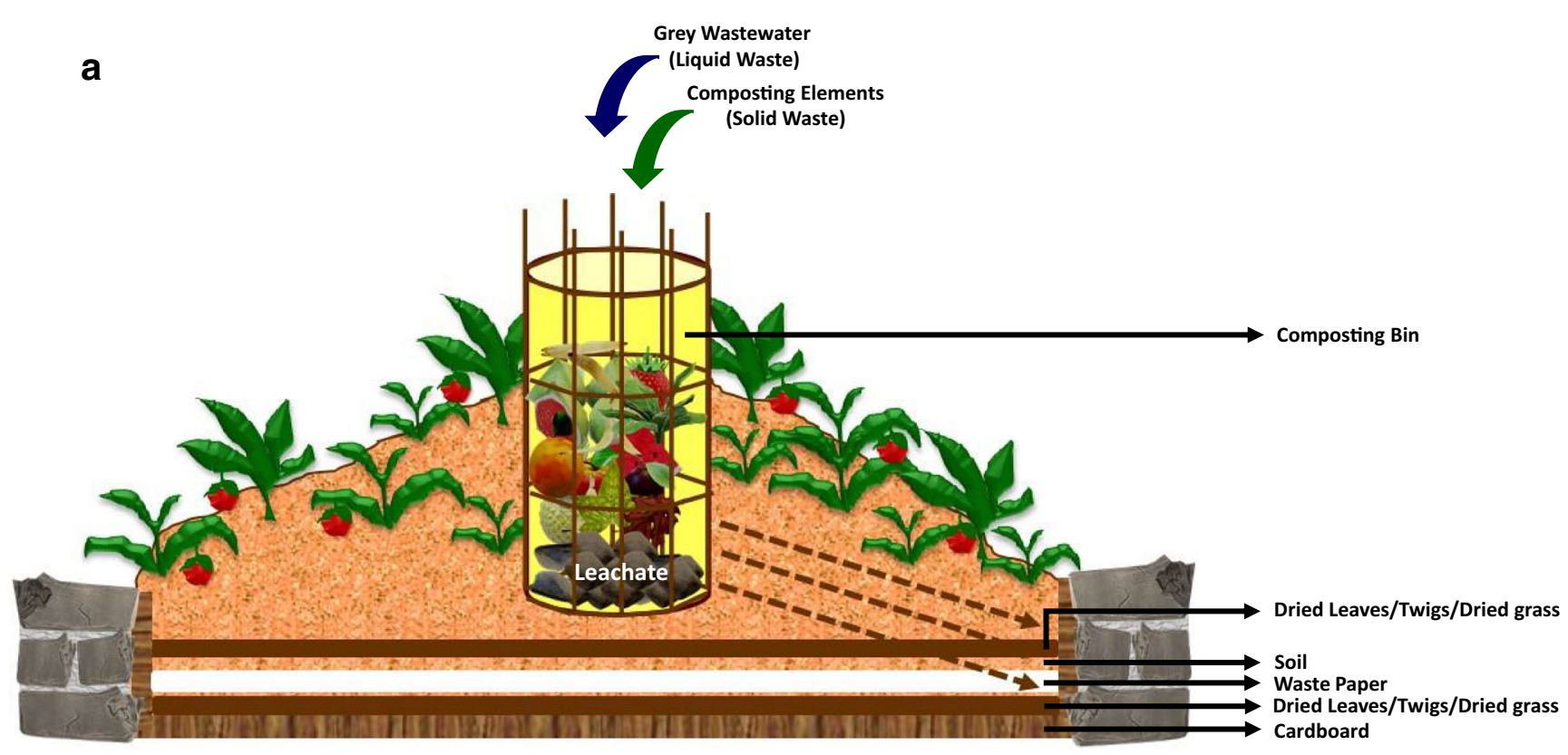

b

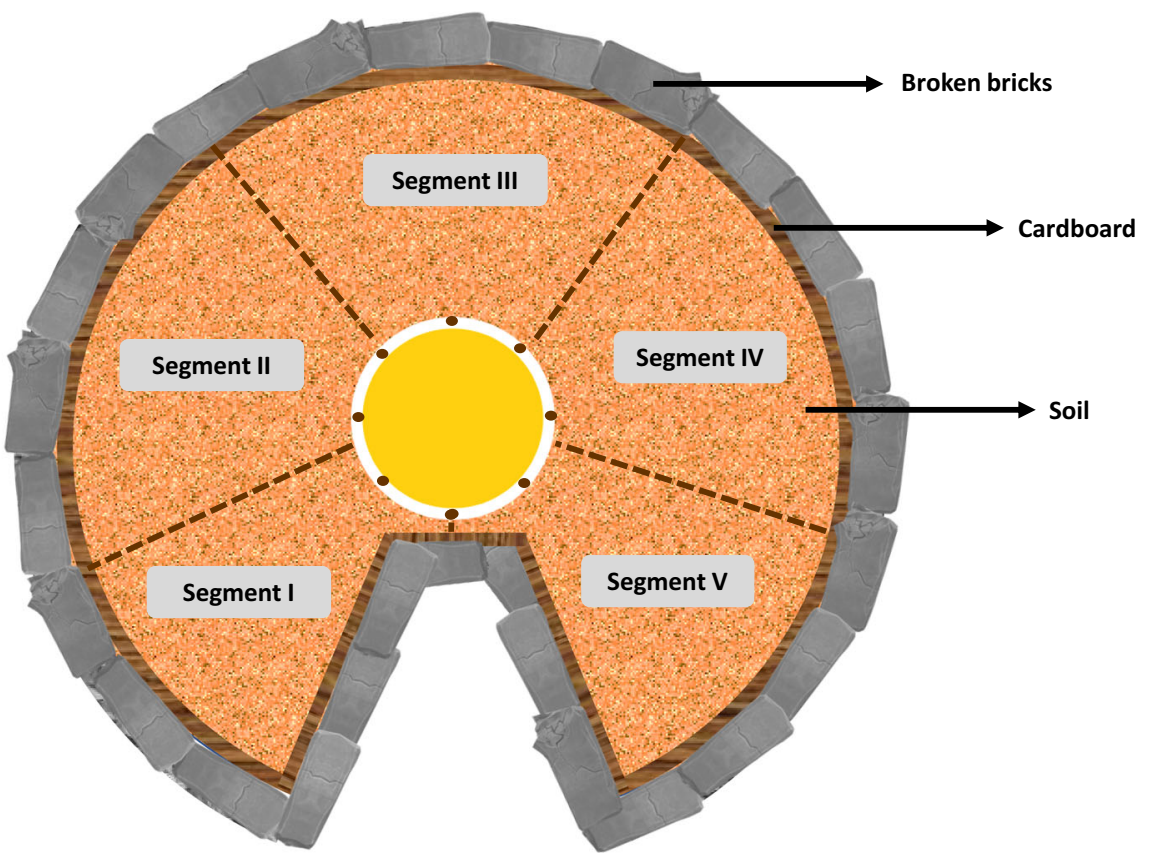

Segment I - for cultivation of vegetables

Segment III - for cultivation of herbs

Segment $V$ - for cultivation of fruits

Segment II - for cultivation of microgreens

Segment IV - for cultivation of flowers

Fig. 1 a Schematic cross section of KHG. b Top view of KHG segments

event) along with the addition of $500 \mathrm{~mL}$ of grey water. The compost basket was fed to cover approximately $70 \%$ of the bin height (0.09-0.2 $\mathrm{m}$ above the top soil layer of the KHG). Intermittent watering (weekly twice) was done to the composting basket. The bin was closed on top to avoid leaching of the nutrients during heavy rains. Scheduled and frequent watering is not required for these types of gardens as they are engineered to retain water for a longer period of time (https://www.engledow.com/green-scene/2013/12/how-tocreate-a-keyhole-garden/; Allen 2018). The liquid released from biologically decomposed organic matter comprises carbon $(\mathrm{C})$, nitrogen $(\mathrm{N})$, phosphorus $(\mathrm{P})$, and potassium $(\mathrm{K})$ 


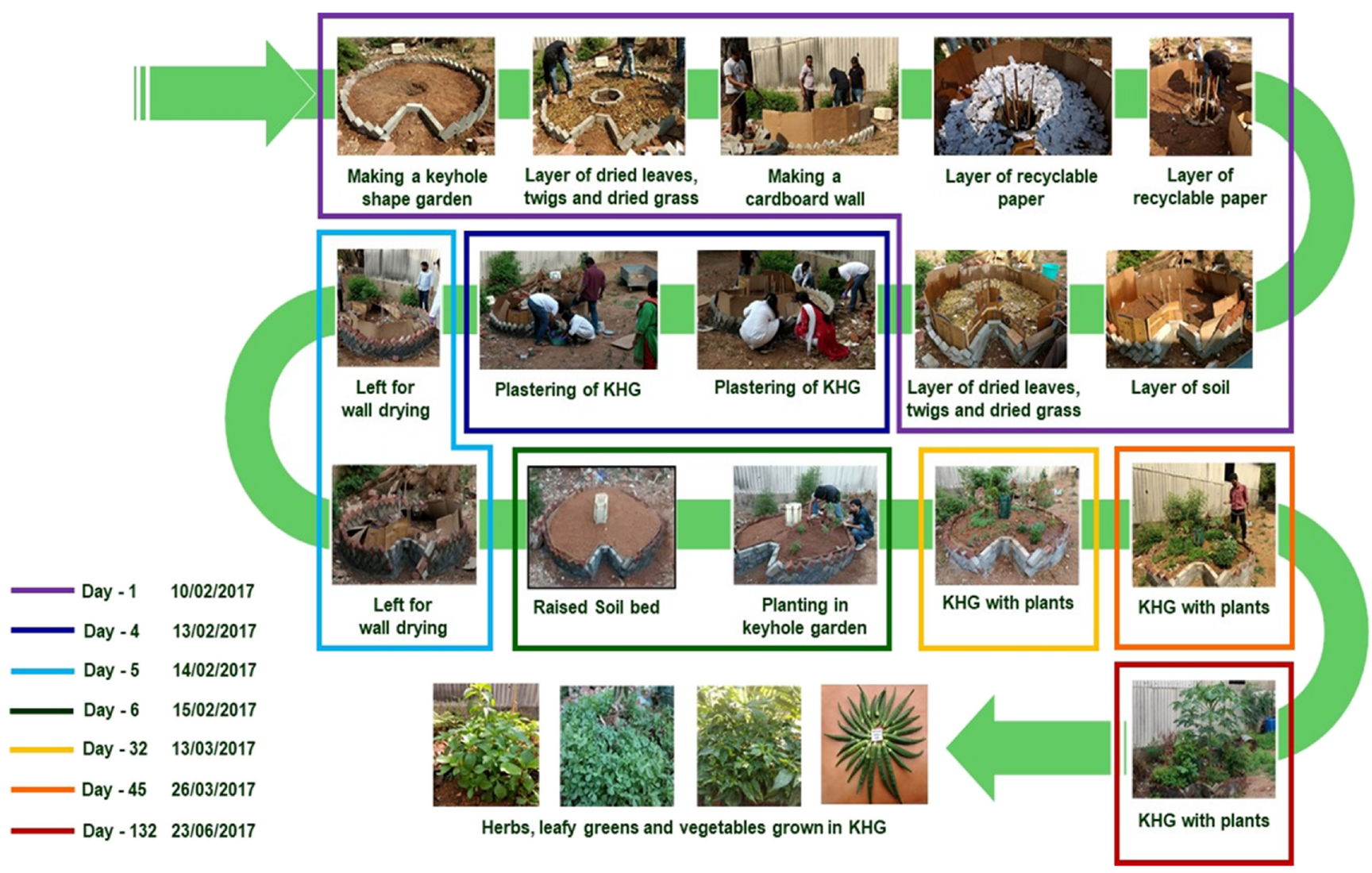

Fig. 2 Step by step construction of KHG at CSIR-IICT

(Sanadia et al. 2019). The volume of liquid was majorly dependent on the moisture content of food waste and the amount of water used for watering. The water while seeping into the soil bed moves along the bin and carries nutrients, thus aiding in plant's growth (Allen 2018). Biologically produced composting liquid solubilizes soil phosphate which is essential for plant's growth and its metabolic activities (Huang et al. 2017; Sarkar et al. 2019).

\section{Productivity}

After the soil bed was set for 2 days, on 16th February, 2017, the KHG was segregated into five segments, each designated for the growth of vegetables, fruits, herbs, and ornamental plants (Figs. 1 and 4). Vegetables or leafy greens can be chosen based on the staple diet, on the nutritional values, or on their ability to grow in small areas with limited nutrients. In this study, okra (Abelmoschus esculentus), tomato (Solanum lycopersicum $L$ ), and green chillies (Capsicum annuum) were chosen to be cultivated in the first vegetable segment due to their easy growth and the nutritional value they offer (Fig. 5). The second segment of the KHG was sowed with fenugreek (Trigonella foenumgraecum) and coriander (Coriandrum sativum) seeds for the cultivation of microgreens, which grow annually and are a rich source of vitamins and minerals (Önder 2018). The third segment of the KHG was planted with herbs like mint (Mentha spicata), basil (Ocimum basilicum), tulsi (Ocimum tenuiflorum), and insulin plants (Costus igneus),
Fig. 3 Fabrication of the composting bin which was incorporated in the KHG
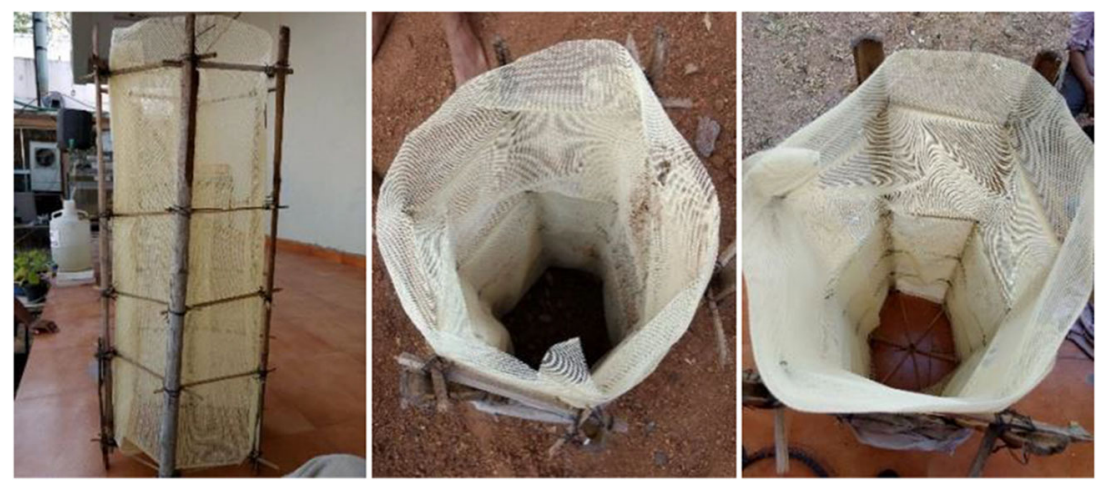
a

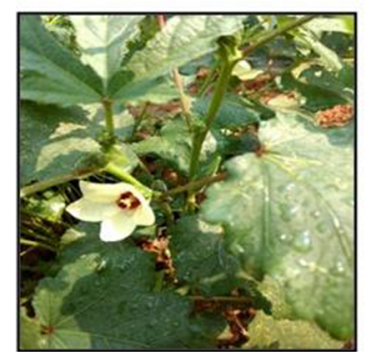

d

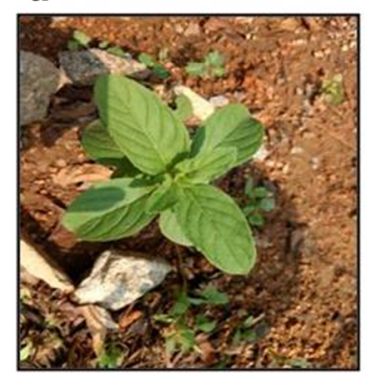

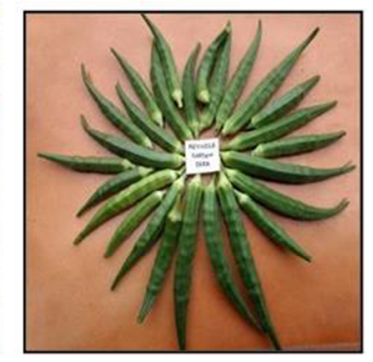

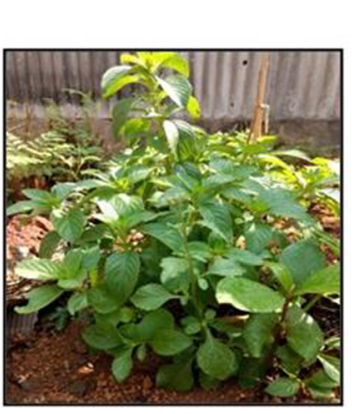

b

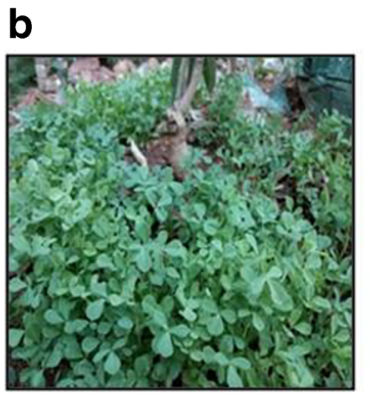

e

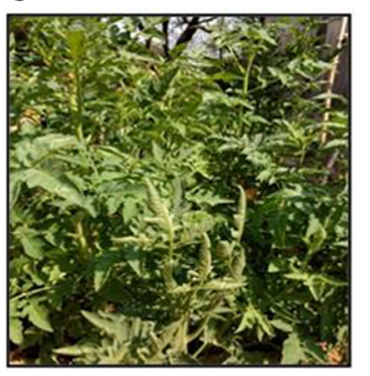

C
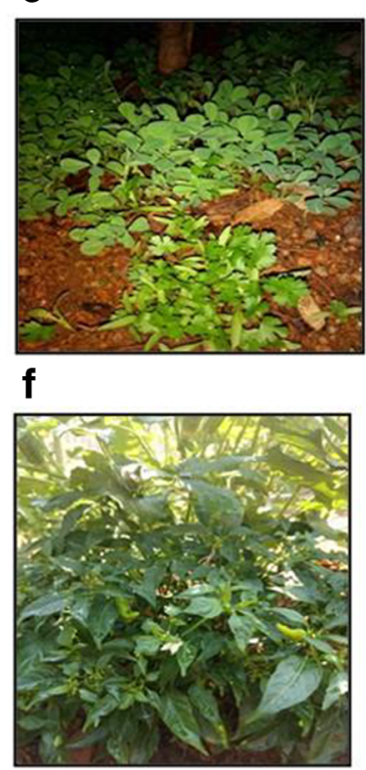

g

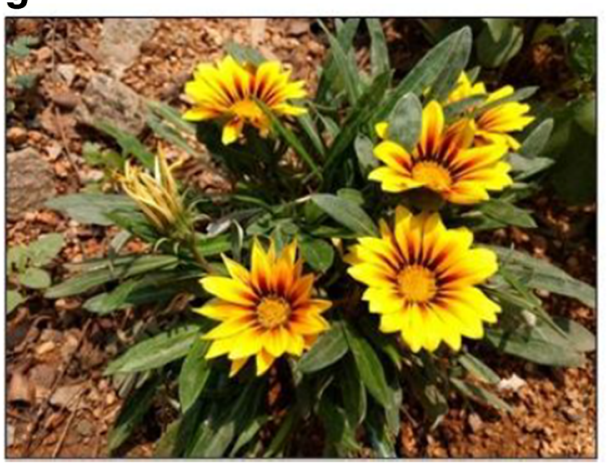

Fig. 4 Various vegetable and ornamental plants cultivated in the KHG. a) Okra (Lady's Finger); b) Fenugreek; c) Coriander leaves; d) Hybrid MintTulsi; e) Tomato; f) Green chilly plants; g) Treasure Flower

which possess medicinal value. The fourth segment was planted with attractive flowers like Gazania daisy (Gazania rigens) - a treasure flower, coloured daisies, and jasmine (Jasminum sambac). Planting flowers in the KHG attracts pollinators like bees and butterflies which increase pollination rates and the harvest as well (https://ento.psu.edu/pollinators/resources-andoutreach/what-are-pollinators-and-why-do-we-need-them). The fifth segment was used to plant fruit saplings such as pomegranate (Punica granatum), papaya (Carica papaya), and sapodilla (Manilkara zapota). However, the time taken for
Fig. 5 Miniature KHG for kitchen and indoor usage

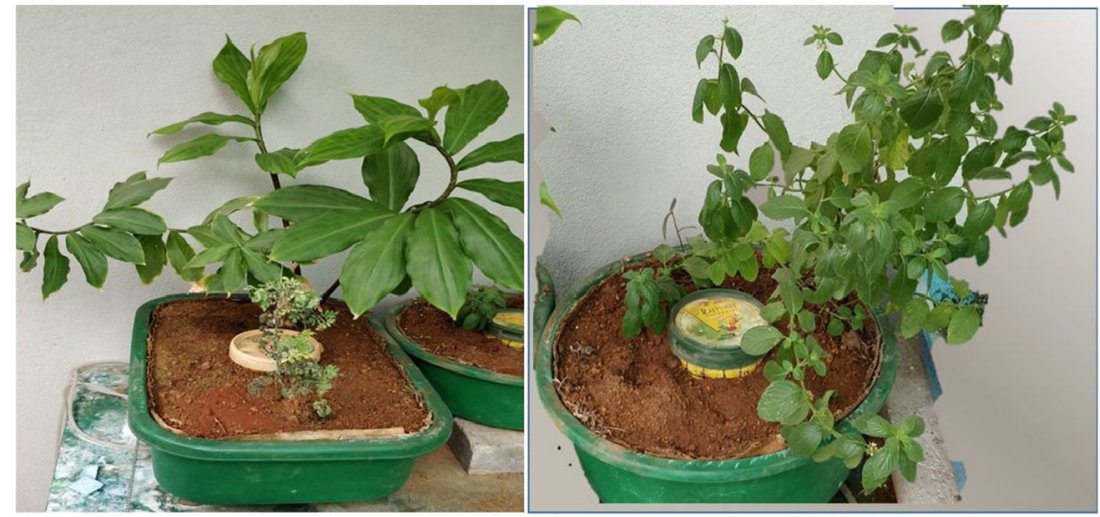


the growth of these plants was too long and fruiting was observed after 30-36 months from the date of planting. After planting the plants and seeds in the designated segments, watering of the KHG was done. The seeds of tomato, green chilli, okra, coriander, fenugreek, and saplings of pomegranate, papaya, and sapodilla were sowed on 17th February, 2017 and their growth was observed within a week from sowing. Growth of leafy greens was much faster compared to vegetables, herbs, and flowers because of their faster germination rates (Figs. 4 and 5). Chillies, okra, and tomato plants took more than a month of time for their production. After 1 year, growth of fruits like pomegranate, papaya, and sapodilla was observed. Addition of biogenic solid and liquid wastes into the composting bin not only aided in the growth of plants but also helped in maintaining the premises clean and wastefree. Additionally, the use of waste material for the construction of KHG also fostered the concept of recycling and reuse. Above all, as a part of numerous community outreach programs carried out by the Institute, students from various schools and colleges who visited the lab also had an opportunity to understand the concept of farming, recycling, and waste management and were enthusiastic in trying out in their own backyards.

\section{Variations in KHG}

Various kinds of KHGs can be constructed within a very less space (small foot prints) in a garden or backyard (Fig. 5). The variants include cascading KHG, independent accessible KHG, and sunseeker KHG (https://www.vitagardens.com/ products/; Allen 2018). All these KHGs can be easily constructed with the locally available waste materials in a small area. In cascading KHG, the composting basket extends from the top to the very bottom, providing nutrients to the garden bed (https://www.vitagardens.com/products/). Independent accessible KHGs are mainly designed for physically challenged people who can cultivate crops with ease. Another kind of variant is the sunseeker-raised bed which can be easily moved, accessed, and maintained. All these KHGs will be advantageous in the urban communities as they are simple, easy to build and maintain which ensures effortless gardening, uses much less water, and also overcomes space constraints in the urban areas. Inspired from the variations of KHG, as a part of the present case study, another variation of KHG which is much smaller in size was also constructed. It was constructed using tubs layered with dried leaves, twigs, waste paper, soil, and a compost bin which were supplemented with the kitchen, vegetable, and fruit wastes and grey water (Fig. 5). Until the present day (3 years of construction), the KHG is still operational with a minimum maintenance (Fig. 6).

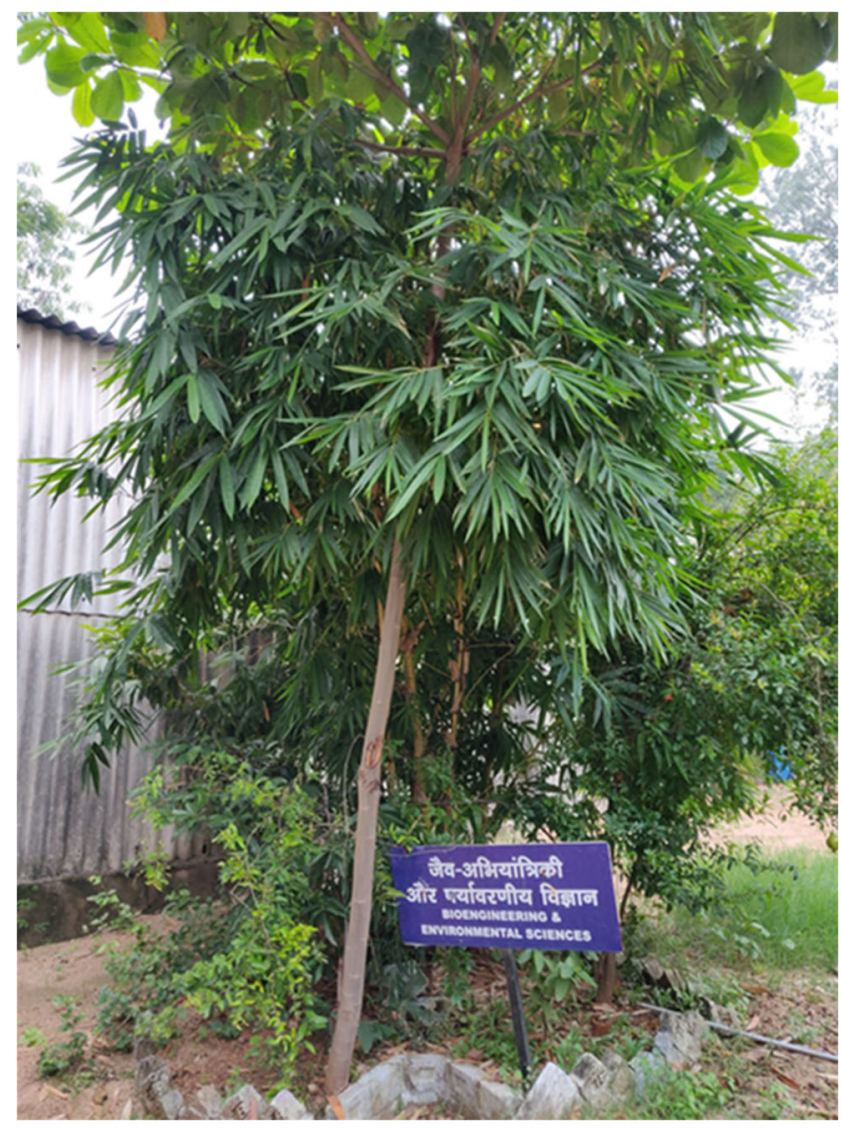

Fig. 6 A functional KHG after 3 years of construction

\section{Overcoming Ecological Challenges Through KHG}

Moving from a linear agricultural practice to a circular approach has the potential to reduce pollution and GHG emissions, increase carbon sequestration in soil, and reduce both energy and water usage. It also helps in minimizing the use of chemical fertilizers. Limiting the use of fertilizers will help in replenishing back the $\mathrm{N}, \mathrm{P}$, and $\mathrm{K}$ to the soil and closing the nutrient loops. The $\mathrm{N}$ and $\mathrm{P}$ in chemical fertilizers are generally produced via synthetic routes or mining of phosphate rocks, which are expected to get depleted in few decades. Moreover, industrial routes of production are incurring substantial energy inputs ( $2 \%$ of the world's energy) and contribute significant amounts of GHG emissions (Kennedy et al. 2010; EMF 2017). The key feature of KHGs is their productive use of waste as compost. The organic waste generated in huge quantities in the urban areas can be considered as a valuable resource in the urban biocycles. The KHGs are also extremely environmentally beneficial due to their waterconserving adaptations. The natural resistance to drought offered by the nutrients and water in the compost basket makes it ideal in cities where water availability is a major concern (Allen 2018). The gardens can also utilize alternative water sources such as captured rainwater and grey water, 
Fig. 7 A circular recycling design of $\mathrm{KHG}$ right from construction until composting

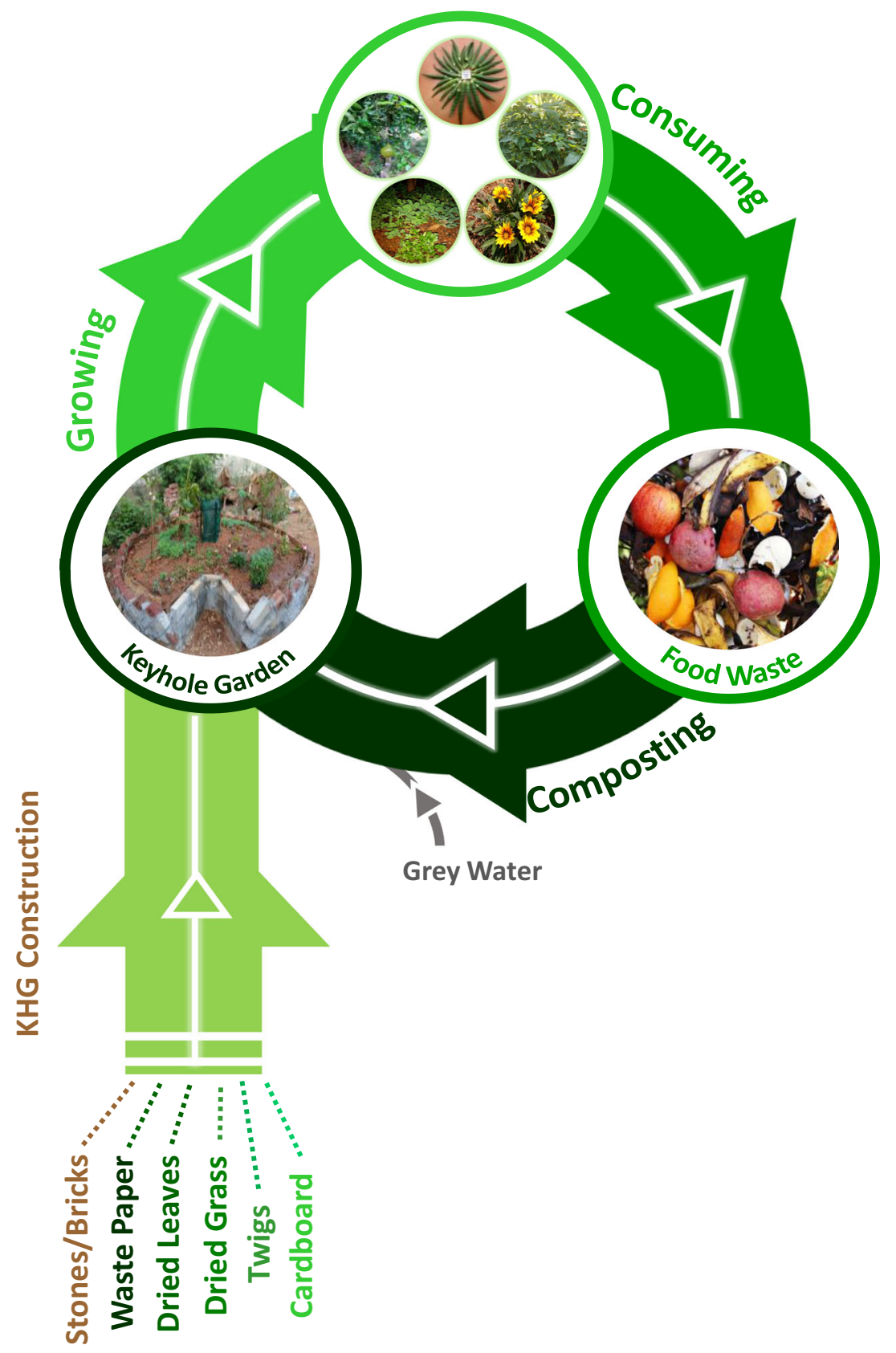

contributing to the conservation of the limited fresh water available in the urban areas (Pachpute et al. 2017). The technical materials can be used for the construction of the garden, minimizing the cost of recycling or remanufacturing (EMF 2017). The recovery and recycling of nutrients from wastes will act as fertilizers in the KHG, develop healthy soils and soil fertility, and avoid the use of chemical fertilizers (Altieri et al. 2012). If the KHGs are utilized to their fullest productive capacities, food can be grown locally, the supply chains can be shortened rendering resilience, and the relationships between the producers, processors, retailers, and consumers can be redefined.
In the Indian context, KHG can be one of the solutions for population growth, rapid urbanization, and low cultivable land availability in both rural and urban areas. With the current population of 1.34 billion and having a growth rate of $1.2 \%$, it is always a challenge on food security. Measures like KHG can bring down food scarcity. KHG can also be considered a viable option for increasing urban population living in cities/ towns having limited availability of space. The compact design of KHG would help in cultivating essential food crops and fruits in limited areas like terrace, balconies, kitchen window, and back garden throughout the year. It can be maintained using the daily generated organic household waste from 
Fig. 8 a Sustainable Development Goals (SDGs) that support organic farming (Organic Agriculture and the Sustainable Development Goals, Simon de Schaetzen 2019). b Goals to deal with food and agriculture in a sustainable way in 2030 agenda (http://www.fao.org/sustainabledevelopment-goals/en/)

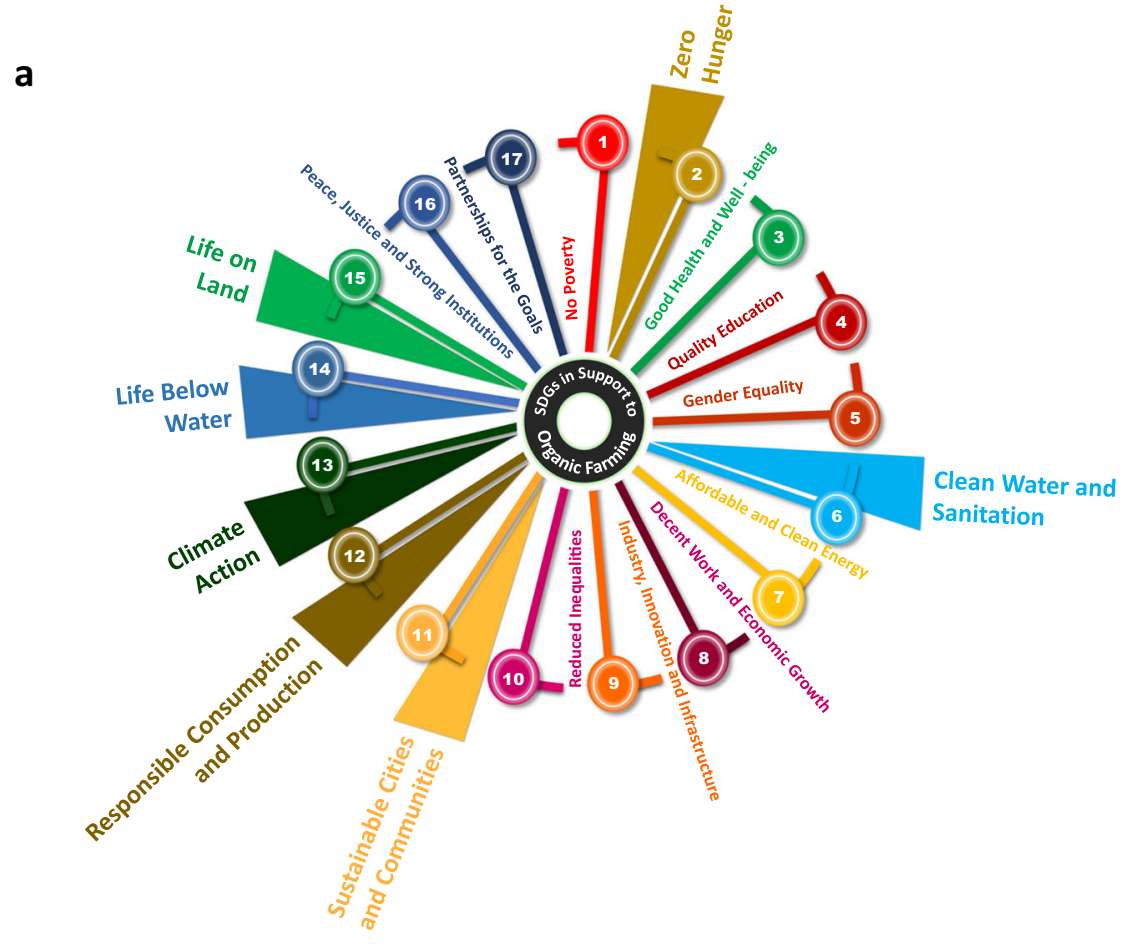

b

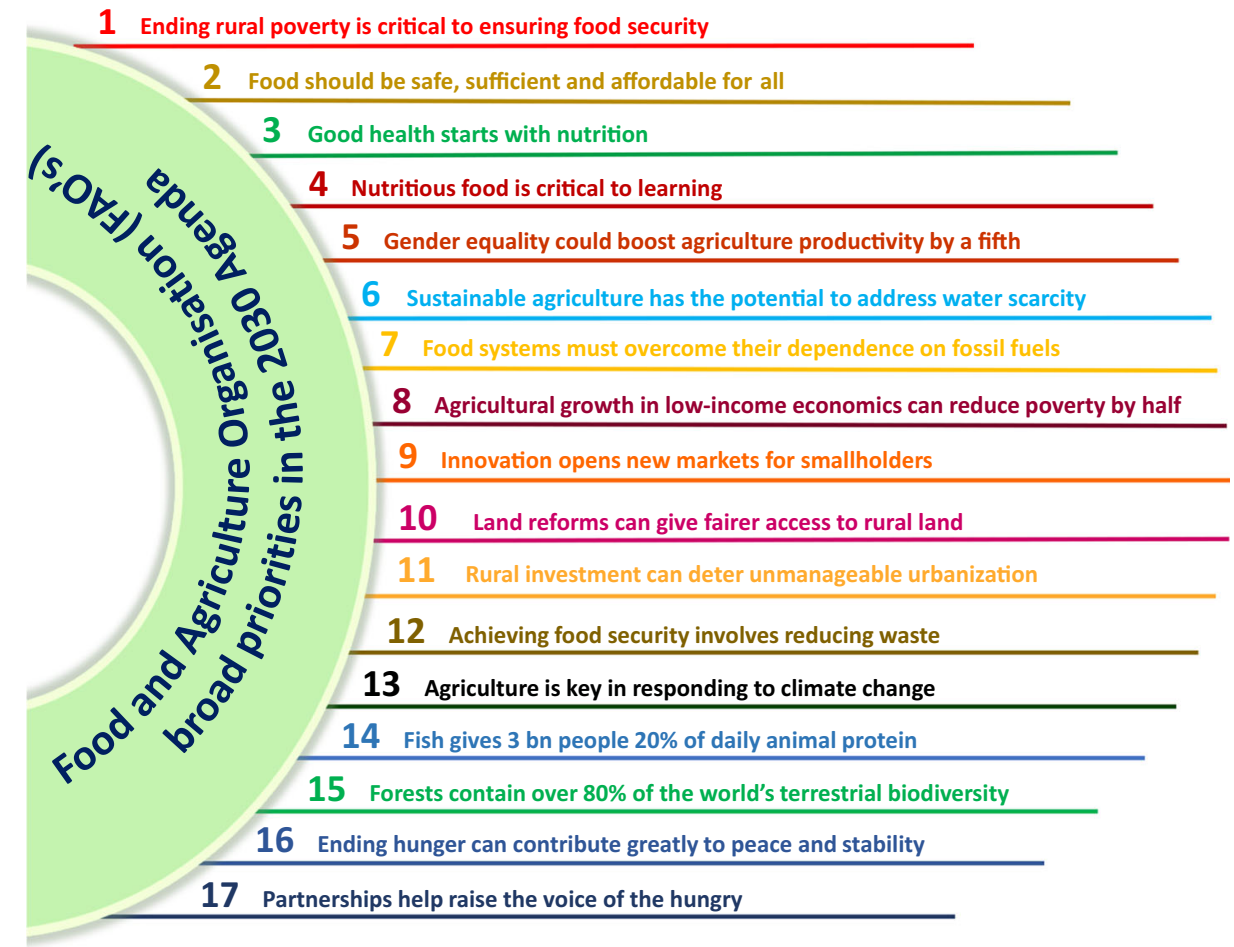

the kitchen. In the rural setup which comprises $60 \%$ of the population, the application of KHG would help in overcoming malnutrition and droughts through sustainable farming (Nazirkhan 2016). KHGs would provide an additional income for a family and also healthy lifestyle as the use of fertilizers is minimized. These sustainable gardens can be managed by individuals, cooperatives, private organizations, and government institutions. The KHGs can also be a great addition to education systems such as schools to foster the concepts of sustainability practices among students. Thus, the KHG is a 
good example of a circular design which is climate-friendly and sustainable and helps in saving space along with waste and nutrient recycling (Fig. 7).

\section{KHG to Achieve Sustainable Development Goals-Fostering Awareness}

The KHGs can be considered a strategy that aligns with most of the Sustainable Development Goals (SDGs). SDG-2 which focuses on ending hunger, achieving food security, improved nutrition, and promoting sustainable agriculture can be bolstered by practices offered by the KHG (Fig. 8). Under SDG-2 target, 2.4 ensures food production systems which are resilient to climate change but produce quality food. This goal can also be supported by the KHG, whose basic principle is to produce food in drought-prone areas. A KHG not only impacts SDG-2 but also impacts SDG-6, -13 , and -15 which are directly related to soil and water. SDG-6 which focuses on avoiding the use of chemical-based pesticides and fertilizers for farming (FAO 2017) can also be aligned with KHG. Cities house over $54 \%$ of the population, and this trend is expected to rise by $5 \%$ by 2030 (DESA U 2018). This calls for more supply of food in the urban areas to meet the food demands of the growing population. Keeping this in view, SDGs have highlighted the importance of agriculture and farming in cities through SDG-11, making them resilient and sustainable. Innovations in this regard like the use of rooftop greenhouses and edible green walls, hydroponics, aquaponics, and indoor and vertical farms which use less space to grow and can feed enough for an individual on a daily basis are being encouraged (Halliday and Hawkes 2017). Responsible consumption and production (SGD-12) and SDG-13 (climate action) can also be aligned with the KHG as it avoids the use of chemical-based fertilizers that affect climate (IFOAM 2012). In addition, the concept of the KHG can also be aligned with SDG-14 (life below water) which discusses issues such as soil run-off from residents and industries to the seas, rivers, and groundwater causing catastrophic dead zones (Diaz and Rosenberg 2008). Although the task of mitigating climate change and achieving the SDGs is indeed formidable with the KHG alone, many other measures can be undertaken to support this endeavour that favours preservation of our planet.

\section{Future Perspectives}

Till date, increase in the productivity has been a key parameter to measure the success of agriculture and its contribution in boosting the economy. However, discussions worldwide are tenaciously being raised about the catastrophic consequences of the modern agricultural practices on human health and environment. On the other hand, it is also believed that this climate change can be reversed by regenerative agricultural practices which are capable of enhancing the soil as a carbon sink. In this context, the current perspective highlights the multifunctional role of regenerative agricultural practices, particularly permaculture and the KHG in urban concentrates. These concepts could enable to rethink the socio-ecological functions and develop an economy inspired by principles of $\mathrm{CE}$ and regenerative practices in urban agglomerates. Circular food practices and food networks based on natural resources in line with the biological cycles of CE can be revitalized in urban areas. In addition, farming activities within the urban boundaries and the peri-urban areas can be encouraged, making cities resilient and self-sufficient. When food is grown in the backyard, it can renew a sense of connection with the food system among the people in urban areas and encourage them to adopt healthy diets. In addition, through regenerative agriculture, food with better nutritive quality and shelf life can be obtained, and it can also reduce the amount of plastic material used for packaging. More importantly, the KHG can be implemented with low investment costs and less maintenance. It can also be considered as an attractive strategy to empower women in the rural areas. The KHG could be considered a gardening practice with a touch of sustainability and can serve as an entry point to engage not just farmers but a wider group of individuals. Due to their inherent tendency to operate at a smaller scale, these can serve as biodiversity centres, experimental hubs, and demonstration sites.

Acknowledgements The authors wish to thank the Director, CSIR-IICT, for supporting the research (IICT Manuscript No. IICT/Pubs./2020/179). We also acknowledge the support of Md. Pasha, K. Venu Srivastav, K. Swathi and dissertation students of 2017 batch - K. Shashidhar Reddy, S. Sushma, Sandeep, V. Sai Pranav, K. Sai Krishna, G. Balu, and B. Venkatesh during construction of the KHG.

\section{Compliance with Ethical Standards}

Competing Interests The authors declare that they have no competing interests.

\section{References}

Allen M (2018) Keyhole gardens as the key to environmental sustainability and access to fresh produce in Samoa: a case study of an organic keyhole farm, Independent Study Project (ISP) Collection. 2864

Altieri MA, Ponti L, Nicholls CI (2012) Soil fertility, biodiversity and pest management. Biodiversity and insect pests: key issues for sustainable management, Wiley-Blackwell, pp 72-84.

Arias S, Bissett E, Carney C, Dao L, Garcia A, Malik Z (2013) Keyhole garden a la Tica: organic and sustainable. digital.lib.usf.edu

Billingsley R, Mothunyane M, Thabane M, McLean S (2013) Lessons from Lesotho: how joined-up approach centred on keyhole gardens is tackling linked issues of hunger nutrition and poverty, hunger nutrition climate justice a new dialogue: putting people at the heart of global development, Conference Report from the Hunger, Nutrition and Climate Justice Conference. April 15-16 2013. Conference organizers: Irish Aid, Mary Robinson Foundation: 
Climate Justice CGIAR Research Program on Climate Change, Agriculture and Food Security (CCAFS) and World Food Programme

Braungart M, Mc Donough W (2009) Cradle to cradle: remaking the way we make things. North Point Press, New York

Dahiya S, Katakojwala R, Ramakrishna S, Venkata Mohan S (2020) Biobased Products and Life Cycle Assessment in the Context of Circular Economy and Sustainability. Mater Circ Econ 2:7

Dahiya S, Kumar AN, Sravan JS, Chatterjee S, Sarkar O, Venkata Mohan S (2018) Food waste biorefinery: sustainable strategy for circular bioeconomy. Bioresour Technol 248:2-12. https://doi.org/10.1016/ j.biortech.2017.07.176

De Bon H, Parrot L, Moustier P (2010) Sustainable urban agriculture in developing countries. A review. Agron Sustain Dev 30(1):21-32. https://doi.org/10.1051/agro:2008062

DESA U (2018) World urbanization prospects 2018. United Nations Department for Economic and Social Affairs

Diaz RJ, Rosenberg R (2008) Spreading dead zones and consequences for marine ecosystems. Science 321(5891):926-929

EMF (2013) Towards the circular economy, Ellen MacArthur Foundation

EMF (2017) Urban biocycles, Ellen MacArthur Foundation

EMF (2019) Cities and circular economy for food, Ellen MacArthur Foundation

FAO (2013) Food wastage footprint: impacts on natural resources, Food and Agriculture Organization

FAO (2017) Soil organic carbon: the hidden potential. Food and Agriculture Organization

Gladek E, Fraser M, Roemers G, Muñoz OS, Kennedy E, Hirsch P (2017) The global food system: an analysis. WWF \& Metabolic, Netherlands https://www.metabolic.nl/publication/global-foodsystem-an-analysis

Gren A, Andersson E (2018) Being efficient and green by rethinking the urban-rural divide-combining urban expansion and food production by integrating an ecosystem service perspective into urban planning. Sustain Cities Soc 40:75-82. https://doi.org/10.1016/j. scs.2018.02.031

Gustavsson J, Cederberg C, Sonesson U, Van Otterdijk R, Meybeck A (2011) Global food losses and FW: extent causes and prevention. Rome, FAO

Haas W, Krausmann F, Wiederhofer D, Heinz M (2015) How circular is the global economy? An assessment of material flows, waste production, and recycling in the European Union and the world in 2005. J Ind Ecol 19:765-777. https://doi.org/10.1111/jiec.12244

Halliday CHJ, Hawkes C (2017) What makes urban food policy happen. Insights from five case studies, International Panel of Experts on Sustainable Food Systems

Hemenway T (2015) The permaculture city: regenerative design for urban suburban and town resilience. Publishing, Chelsea Green

Holmgren D (2007) Essence of permaculture. Holmgren Design Services, Hepburn

Holmgren D (2011) Permaculture: principles and pathways beyond sustainability. Permanent Publications, UK

Hu Y, Lin J, Cui S, Khanna NZ (2016) Measuring urban carbon footprint from carbon flows in the global supply chain. Environ Sci Technol 50(12):6154-6163. https://doi.org/10.1021/acs.est.6b00985

Huang H, Zhang D, Zhao Z, Zhang P, Gao F (2017) Comparison investigation on phosphate recovery from sludge anaerobic supernatant using the electrocoagulation process and chemical precipitation. J Clean Prod 141:429-438. https://doi.org/10.1016/j.jclepro. 2016.09.127

IFOAM (2012) Organic agriculture-a strategy for climate change adaptation, International Federation of Organic Agriculture Movements

Katakojwala R, and Venkata Mohan SV (2020) A critical view on the environmental sustainability of biorefinery systems. Curr Opin Green Sust. Chem. 100392
Kennedy C, Steinberger J, Gasson B, Hansen Y, Hillman T, Havranek M, Pataki D, Phdungsilp A, Ramaswami A, Mendez GV (2010) Methodology for inventorying greenhouse gas emissions from global cities. Energy Policy 38:4828-4837. https://doi.org/10.1016/j. enpol.2009.08.050

Leakey RR (2020) A re-boot of tropical agriculture benefits food production rural economies health social justice and the environment. Nat Food 1(5):260-265. https://doi.org/10.1038/s43016-020-0076-z

Nazirkhan (2016) The keyhole garden: a family garden to combat malnutrition Published on September 22 (2016) in Agriculture by Fadya Nazirkhan

Nicholls CI, Altieri MA (2012) Agro-ecological approaches to enhance resilience. Farm Matt 28(2):14-17

Önder A (2018) Coriander and its phytoconstituents for the beneficial effects. Potent Essen Oils 165. https://doi.org/10.5772/intechopen. 78656

Pachpute JS, Pachpute ST, Sane GG, Patil AM (2017) Homestead vegetable gardening using graywater: meeting the need of year-round vegetable requirement of landless and marginal farmers. Contemp Res India 7:3

Peeters B (2011) Permaculture as alternative agriculture. Kasarinlan 26: 422-434 https://journals.upd.edu.ph/index.php/kasarinlan/article/ view/3511/0

Rhodes CJ (2012) Feeding and healing the world: through regenerative agriculture and permaculture. Sci Prog 95(4):345-446. https://doi. org/10.3184/003685012X13504990668392

Sanadia NFA, Van FY, Leea CT, Ibrahimc N, Lid C, Gaod Y, Onge PY, Klemešb JJ (2019) Nutrient in leachate of biowaste compost and its availability for plants. Chem Eng 76. https://doi.org/10.3303/ CET1976229

Sanchez FAC, Boudaoud H, Camargo M, Pearce JM (2020) Plastic recycling in additive manufacturing: a systematic literature review and opportunities for the circular economy. J Clean Prod 264: 121602. https://doi.org/10.1016/j.jclepro.2020.121602

Sarkar O, Chatterjee S, Venkata Mohan S (2019) Acidogenic outlet from biohydrogen reactor as phosphate solubilizing agent for integrated organic farming. J Clean Prod 208:490-498. https://doi.org/10. 1016/j.jclepro.2018.09.213

Strazza C, Magrassi F, Gallo M, Del Borghi A (2015) Life cycle assessment from food to food: a case study of circular economy from cruise ships to aquaculture. Sustain Product Consump 2:40-51. https://doi.org/10.1016/j.spc.2015.06.004

Venkata Mohan S, Nikhil GN, Chiranjeevi P, Reddy CN, Rohit MV, Kumar AN, Sarkar O (2016a) Waste biorefinery models towards sustainable circular bioeconomy: critical review and future perspectives. Bioresour Technol 215:2-12. https://doi.org/10.1016/j. biortech.2016.03.130

Venkata Mohan S, Dahiya S, Velvizhi G, Reddy CN (2016b) Ecovillages: resilient approach to sustainable rural development in Indian context. J Energ Environ Sust 2:55-63

Venkata Mohan S, Dahiya S, Amulya K, Katakojwala R, Vanitha TK (2019) Can circular bioeconomy be fueled by waste biorefineries-a closer look. Bioresour Technol Rep 7:100277. https://doi.org/10. 1016/j.biteb.2019.100277

Venkata Mohan S, Amulya K, Modestra JA (2020) Urban biocyclesclosing metabolic loops for resilient and regenerative ecosystem: a perspective. Bioresour Technol 306:123098. https://doi.org/10. 1016/j.biortech.2020.123098

Wiskerke JS (2015) Urban food systems. In Cities and agriculture, Routledge, 19-43.

World Bank (2018) World development indicators, Available at: https:// datacatalog.worldbank.org/dataset/world-development-indicators. Accessed 16 Sep 2019 